\title{
Common Fixed Point Results for a Class of $(\alpha, \beta)$-Geraghty Contraction Type Mappings in Modular Metric Spaces
}

\author{
Merve Aktay*iD, Murat Özdemir (D) \\ Department of Mathematics, Faculty of Science, Ataturk University, 25240 Erzurum, Turkey.
}

Geliş / Received: 17/09/2019, Kabul / Accepted: 21/02/2020

\begin{abstract}
In this paper, we introduce concepts of generalized $(\alpha, \beta)$ - Geraghty contraction type mappings in modular metric spaces via $(\alpha, \beta)-$ admissible pair in modular metric spaces are essentially weaker than the class of $\alpha$ - Geraghty contraction type mappings. We establish some fixed point and periodic point results for such contractions. Consequently, the obtained results encompass various generalizations of the Banach contraction principle.
\end{abstract}

Keywords: fixed point, modular metric, Geraghty contraction maps

\section{Common Fixed Point Results for a Class of $(\alpha, \beta)$-Geraghty Contraction Type Mappings in Modular Metric Spaces}

\section{$\ddot{\mathbf{O} z}$}

Bu makalede $\alpha$ - Geraghty daraltan tipi dönüşümlerin sınıfindan daha zayıf olan $(\alpha, \beta)$-uygun çifti aracilığıyla genelleştirilmiş $(\alpha, \beta)$ - Geraghty daraltan tipi dönüşüm kavramı Modüler metrik uzaylarda tanıtıldı. Bu tarz dönüşümler için bazı sabit nokta ve periyodik nokta sonuçları verildi. Sonuç olarak elde edilen sonuçlar Banach daraltan ilkesinin çeşitli genelleştirmelerini kapsar.

Anahtar Kelimeler: Sabit nokta, modüler metrik, Geraghty daraltan dönüşümler

\section{Introduction}

It is well known that the Banach's contraction principle (Banach 1922), which is a useful tool in the study of many branches of mathematics and mathematical sciences, is one of the earlier and main results in fixed point theory. Geraghty (1973) proved an interesting generalization of Banach's contraction principle in the setting of complete metric spaces by considering an auxiliary function. Later, Amini-Harandi and Emami (2010) characterized the result of Geraghty in the context of a partially ordered complete metric space, and Caballero et al. (2012) gave some results. Gordji et al. (2012) defined the notion of $\psi$-Geraghty type contraction and Cho et al. (2013) gave some results for alpha-Geraghty contraction type maps. Also Karapınar and Samet (2014) proved that the results of Gordji et al. [14] and all results inspired by the paper of Gordji et al. (2012) are equivalent to existing results in the literature.

On the other hand, to deal with the problems of description of superposition operators, Chistyakov (2010) introduced the notion of

\footnotetext{
*Corresponding Author: merve.ozkan@atauni.edu.tr
} 
modular metric spaces and gave some fundamental results on this topic, whereas some authors introduced the analog of the Banach contraction theorem in modular metric spaces and described the important aspects of applications of fixed point of mappings in modular metric spaces. Some recent results in this direction can be found in (Azadifar, 2013; Chaipunya et al., 2012;

\section{Material and Methods}

Throughout this paper $\mathbb{N}, \mathbb{R}^{+}$and $\mathbb{R}$ will denote the set of natural numbers, positive real numbers, and real numbers, respectively. For this purpose, we remind the class of $F$ all functions $\beta:[0, \infty) \rightarrow 0,1)$ which satisfies the condition: $\beta\left(t_{n}\right) \rightarrow 1$ implies $t_{n} \rightarrow 0$.

Let $\Psi$ denote the class of functions $\psi: \mathbb{R}^{+} \rightarrow$ $\mathbb{R}^{+}$satisfying the following conditions:

- $\psi$ is strictly increasing,

- $\psi$ is continuous,

- $\psi(t)=0$ if and only if $t=0$.

Now, we give some basic concepts and definitions about modular metric spaces.

Definition 2.1 (Chistyakov, 2010) Let $X$ be a nonempty set. A function $\omega:(0, \infty) \times X \times$ $X \rightarrow 0, \infty]$ is said to be a metric modular on $X$ if satisfying, for all $x, y, z \in X$ the following conditions hold:

1. $\omega_{\lambda}(x, y)=0$ for all $\lambda>0, x=y$,

2. $\omega_{\lambda}(x, y)=\omega_{\lambda}(x, y)$ for all $\lambda>0$,

3. $\omega_{\lambda+\mu}(x, y) \leq \omega_{\lambda}(x, y)+\omega_{\mu}(x, y)$ for all $\lambda>0$.

If instead of (i), we have only the condition

1. $\omega_{\lambda}(x, x)=0$ for all $\lambda>0$, then $\omega$ is said to be a (metric) pseudomodular on $X$.
Hussain et al., 2015; Kuaket and Kumam 2011; Kumam, 2004; Padcharoen, 2016).

In this paper, we prove the existence and uniqueness of a fixed and common fixed point of generalized $(\alpha, \beta)$-Geraghty contraction type maps via $(\alpha, \beta)$-admissible and generalized $(\alpha, \beta)$-admissible pair of mappings in the context of a complete modular metric space.

For any $x_{0}$, the set

$$
X_{\omega}\left(x_{0}\right)=\left\{x \in X: \lim _{\lambda \rightarrow \infty} \omega_{\lambda}\left(x, x_{0}\right)=0\right\}
$$

is called a modular metric space generated by $x_{0}$ and induced by $\omega . X_{\omega}$ is independent of generators, we write $X_{\omega}$ instead of $X_{\omega}\left(x_{0}\right)$ and $\omega_{\lambda}(x, y)=\omega(\lambda, x, y)$, for all $\lambda>0$.

The main property of a metric modular $\omega$ on a set $X$ is the following: given $x, y \in X$, the function $\left.\quad 0<\lambda \mapsto \omega_{\lambda}(x, y) \in 0, \infty\right]$ is nonincreasing on $(0, \infty)$. In fact, if $0<\mu<$ $\lambda$, then

$$
\begin{aligned}
\omega_{\lambda}(x, y) & \leq \omega_{\lambda-\mu}(x, x)+\omega_{\mu}(x, y) \\
& =\omega_{\mu}(x, y) .
\end{aligned}
$$

Obviously, a metric modular $\omega$ on a set $X$ is nonincreasing with respect to $\lambda>0$.

Chaipunya et al. (2012) changed the notion of convergent and Cauchy sequences in modular metric spaces under the direction of Mongkolkeha et al. (2011).

Definition 2.2 (Chaipunya et al., 2012; Cho et al., 2013) Let $X_{\omega}$ be a modular metric space and $\left\{x_{n}\right\}$ be a sequence in $X_{\omega}$.

1. A point $x \in X_{\omega}$ is called a limit of $\left\{x_{n}\right\}$ if, for each $\lambda, \varepsilon>0$, there exists $n_{0} \in \mathbb{N}$ such that $\omega_{\lambda}\left(x_{n}, x\right)<\varepsilon$ for all $n \geq n_{0}$. A 
sequence that has a limit is said to be convergent (or converges to $x$ ), which is written as $\lim _{n \rightarrow \infty} x_{n}=x$.

2. A sequence $\left\{x_{n}\right\}$ in $X_{\omega}$ is said to be a Cauchy sequence if, for each $\lambda, \varepsilon>0$, there exists $n_{0} \in \mathbb{N}$ such that $\omega_{\lambda}\left(x_{n}, x_{m}\right)<\varepsilon$ for all $n, m \geq n_{0}$.

3. Let $X_{\omega}$ be a modular metric space. If every Cauchy sequences in $X_{\omega}$ converges, $X_{\omega}$ is said to be complete.

Definition 2.3 (Chistyakov, 2011) A modular $\omega$ on $X_{\omega}$ is said to satisfy the $\Delta_{2}$-condition if for a sequence $\left\{x_{n}\right\} \subset X_{\omega}$ and $x$ in $X_{\omega}$, there exists a number $\lambda>0$, possibly depending on $\left\{x_{n}\right\}$ and $x$, such that $\lim _{n \rightarrow \infty} \omega_{\lambda}\left(x_{n}, x\right)=0, \quad$ then $\lim _{n \rightarrow \infty} \omega_{\frac{\lambda}{2}}\left(x_{n}, x\right)=0$. This implies that $\lim _{n \rightarrow \infty} \omega_{\lambda}\left(x_{n}, x\right)=0$ for all $\lambda>0$.

Henceforwards, in this paper we assume that $\omega$ is a modular on $X_{\omega}$ and satisfy in the $\Delta_{2}$-condition on $X_{\omega}$.

\section{Results}

Samet et al. (2012) gave the definition of $\alpha$-admissible and later Aydi (2015) gereneralized this definition. Also, Chandok (2015) introduced $(\alpha, \beta)$-Geraghty type-I rational contractive mapping and $(\alpha, \beta)$-admissible mapping. Regarding this, Chandok (2015) gave some results in complete metric spaces. Now we give the definition of $(\alpha, \beta)$-admissible pair in modular metric spaces.

Definition 3.1 Let $X_{\omega}$ be a modular metric space and $T: X_{\omega} \rightarrow X_{\omega}$ be a map and $\alpha: X_{\omega} \times X_{\omega} \rightarrow \mathbb{R}^{+}$be a function. Then
1. $T$ is said to be $\alpha$-admissible if $\alpha(x, y) \geq 1$ implies $\alpha(T x, T y) \geq 1$ for all $x, y \in X$.

2. A self mapping $T$ on $X_{\omega}$ is said to be triangular $\alpha$-admissible if:

(a) $T$ is $\alpha$-admissible,

(b) $\alpha(x, z) \geq 1$ and $\alpha(z, y) \geq 1$ imply $\alpha(x, y) \geq 1$.

3. Let T: $X_{\omega} \rightarrow X_{\omega}$ be a map and $\alpha: X_{\omega} \times$ $X_{\omega} \rightarrow \mathbb{R}^{+}$be a function. Then $T$ is said to be $\alpha$-orbital admissible if $\alpha(x, T x) \geq 1$ implies $\alpha\left(T x, T^{2} x\right) \geq 1$.

Definition 3.2 Let $X_{\omega}$ be a modular metric space and $T, S: X_{\omega} \rightarrow X_{\omega}$ be maps and $\alpha, \beta: X_{\omega} \times X_{\omega} \rightarrow \mathbb{R}^{+}$be two functions. Then

1. $(T, S)$ is said to be $(\alpha, \beta)$-admissible if $\alpha(x, y) \geq 1$ and $\quad \beta(x, y) \geq 1 \quad$ implies $\alpha(T x, S y) \geq 1, \quad \alpha(S x, T y) \geq 1 \quad$ and $\beta(T x, S y) \geq 1, \beta(S x, T y) \geq 1$ for all $x, y \in$ $X$.

2. $T$ is said to be $(\alpha, \beta)$-admissible if $\alpha(x, y) \geq 1$ and $\quad \beta(x, y) \geq 1 \quad$ implies $\alpha(T x, T y) \geq 1$ and $\beta(T x, T y) \geq 1$ for all $x, y \in X$.

3. $X_{\omega}$ is $(\alpha, \beta)$-regular if $\left\{x_{n}\right\}$ is a sequence in $X_{\omega}$ such that $x_{n} \rightarrow x \in X_{\omega}$, $\alpha\left(x_{n}, x_{n+1}\right) \geq 1, \beta\left(x_{n}, x_{n+1}\right) \geq 1$, for all $n$, there exists a subsequence $\left\{x_{n_{k}}\right\}$ of $\left\{x_{n}\right\}$ such that $\alpha\left(x_{n_{k}}, x_{n_{k}+1}\right) \geq 1, \quad \beta\left(x_{n_{k}}, x_{n_{k}+1}\right) \geq 1$ for all $k \in \mathbb{N}$ and $\alpha(x, T x) \geq 1, \alpha(x, S x) \geq$ 1 , and $\beta(x, T x) \geq 1, \beta(x, S x) \geq 1$.

4. Self mappings $T$ and $S$ on $X_{\omega}$ are said to be triangular $(\alpha, \beta)$-admissible if:

(a) $(T, S)$ is $(\alpha, \beta)$-admissible,

(b) $\alpha(x, z) \geq 1$ and $\alpha(z, y) \geq 1$ imply $\alpha(x, y) \geq 1$ and $\beta(x, z) \geq 1$ and $\beta(z, y) \geq$ 1 imply $\beta(x, y) \geq 1$ for all $x, y, z \in X_{\omega}$. 
Definition 3.3 Let $T: X_{\omega} \rightarrow X_{\omega}$ be a map and $\alpha: X_{\omega} \times X_{\omega} \rightarrow \mathbb{R}^{+}$be a function. Then $T$ is said to be triangular $\alpha$-orbital admissible if $T$ is $\alpha$-orbital admissible and $\alpha(x, y) \geq 1 \quad$ and $\quad \alpha(y, T y) \geq 1 \quad$ imply $\alpha(x, T y) \geq 1$.

Obviously, every $\quad(\alpha, \beta)$-admissible mapping is an $\alpha$-admissible mapping. For examples, see (Samet et al., 2012 and Aydi, 2015) and for farther detail see (Arshad et al., 2016) and cited therein.

Lemma 3.4 Let $T: X_{\omega} \rightarrow X_{\omega}$ be a triangular $\alpha$-admissible mapping. Assume that there exists $x_{1} \in X$ such that $\alpha\left(x_{0}, T x_{0}\right) \geq 1$. Define a sequence $\left\{x_{n}\right\}$ by $x_{n+1}=T x_{n}$. Then, we have $\alpha\left(x_{n}, x_{m}\right) \geq 1$ for all $m, n \in$ $\mathbb{N}$ with $n<m$.

Proof Since $T$ is triangular $\alpha$-admissible and $\alpha\left(x_{0}, T x_{0}\right) \geq 1$, we deduce that $\alpha\left(x_{1}, x_{2}\right)=\alpha\left(T x_{0}, S x_{1}\right) \geq 1$. By continuing this process, we get $\alpha\left(x_{n}, x_{n+1}\right) \geq 1$ for all $n \geq 0$. Assume that $\alpha\left(x_{n}, x_{m}\right) \geq 1$. We shall prove that $\alpha\left(x_{n}, x_{m+1}\right) \geq 1$, where $m>n$. Since $T$ is triangular $\alpha$-admissible and $\alpha\left(x_{m}, x_{m+1}\right) \geq 1$, we get that $\alpha\left(x_{n}, x_{m+1}\right) \geq$ 1 . Therefore, we obtained that $\alpha\left(x_{n}, x_{m}\right) \geq$ 1 for all $m, n \in \mathbb{N}$ with $n<m$.

Samet et al. (2012) gave generalized $\alpha$-Geraghty contraction type map. Later Arshad et al. (2016) give some generalizations in metric spaces.

Now, we give the definition of generalized $(\alpha, \beta)$-Geraghty contraction type mappings in modular metric spaces.

Definition 3.5 Let $X_{\omega}$ be a complete modular metric space, $\quad \alpha, \beta: X_{\omega} \times X_{\omega} \rightarrow \mathbb{R}^{+}$be functions, and two maps $T, S: X_{\omega} \rightarrow X_{\omega}$ is called $a$ pair of generalized $(\alpha, \beta)-$ Geraghty contraction type mappings if there exists $\gamma \in \mathrm{F}$ such that for all $x, y \in$ $X_{\omega}$,

$$
\begin{aligned}
& \alpha(x, y) \beta(x, y) \psi\left(\omega_{1}(T x, S y)\right) \\
& \leq \gamma\left(\psi\left(M_{T, S}(x, y)\right)\right) \psi\left(M_{T, S}(x, y)\right),
\end{aligned}
$$

where

$$
\begin{aligned}
& M_{T, S}(x, y) \\
& =\max \left\{\omega_{1}(x, y), \omega_{1}(x, T x), \omega_{1}(y, S y),\right. \\
& \left.\frac{\omega_{2}(x, S y)+\omega_{2}(y, T x)}{2}\right\} .
\end{aligned}
$$

Theorem 3.6 Let $X_{w}$ be a complete modular metric space, $\alpha, \beta: X_{w} \times X_{w} \rightarrow \mathbb{R}^{+}$be functions, and let $T, S$ be self-mappings on $X_{w}$ satisfying the following conditions:

1. $(T, S)$ is a pair of generalized $(\alpha, \beta)$-geraghty contraction type mappings,

2. $(T, S)$ is triangular $(\alpha, \beta)$-admissible pair,

3. There exists $x_{0} \in X_{w}$ such that $\alpha\left(x_{0}, T x_{0}\right) \geq 1$ and $\beta\left(x_{0}, T x_{0}\right) \geq 1$,

4. $T$ and $S$ are continuous.

Then $(T, S)$ has a common fixed point.

Proof From the hypothesis (3) of Theorem 3.6, there exists a point $x_{0} \in X_{w}$ such that $\alpha\left(x_{0}, T x_{0}\right) \geq 1$. Let $x_{1}=T x_{0}$ and $x_{2}=$ $S x_{1}$. Define a sequence $\left\{x_{n}\right\}$ by $x_{2 n+2}=$ $S x_{2 n+1}$ and $x_{2 n+1}=T x_{2 n}$ for all $n \geq 0$. First of all, we show that $\alpha\left(x_{n}, x_{n+1}\right) \geq 1$ and $\alpha\left(x_{n+1}, x_{n}\right) \geq 1$ for all $n \geq 0$. Since $\alpha\left(x_{0}, T x_{0}\right) \geq 1$, we have $\alpha\left(x_{0}, x_{1}\right) \geq$ 1. Since $(T, S)$ is a generalized $(\alpha, \beta)$-admissible pair of mappings, we have

$$
\alpha\left(x_{1}, x_{2}\right)=\alpha\left(T x_{0}, S x_{1}\right) \geq 1,
$$

and

$$
\alpha\left(x_{3}, x_{2}\right)=\alpha\left(T x_{2}, S x_{1}\right) \geq 1
$$

By induction, we get 


$$
\alpha\left(x_{n}, x_{n+1}\right) \geq 1
$$

for all $n \geq 0$. Similarly,

$$
\beta\left(x_{n}, x_{n+1}\right) \geq 1
$$

for all $n \geq 0$. Since $\gamma \in 0,1)$ and from (3.2) and (3.3), we have

$$
\begin{aligned}
& \psi\left(\omega_{1}\left(x_{2 n+1}, x_{2 n+2}\right)\right) \\
\leq & \alpha\left(x_{2 n}, x_{2 n+1}\right) \beta\left(x_{2 n}, x_{2 n+1}\right) \\
& \psi\left(\omega_{1}\left(T x_{2 n}, S x_{2 n+1}\right)\right) \\
\leq & \gamma\left(\psi\left(M_{T, S}\left(x_{2 n}, x_{2 n+1}\right)\right)\right) \psi\left(M_{T, S}\left(x_{2 n}, x_{2 n+1}\right)\right)
\end{aligned}
$$

where

$$
\begin{gathered}
M_{T, S}\left(x_{2 n}, x_{2 n+1}\right)=\max \left\{\omega_{1}\left(x_{2 n}, x_{2 n+1}\right),\right. \\
\omega_{1}\left(x_{2 n}, T x_{2 n}\right), \omega_{1}\left(x_{2 n+1}, S x_{2 n+1}\right) \\
\left.\frac{\omega_{2}\left(x_{2 n}, S x_{2 n+1}\right)+\omega_{2}\left(x_{2 n+1}, T x_{2 n}\right)}{2}\right\} \\
=\max \left\{\omega_{1}\left(x_{2 n}, x_{2 n+1}\right), \omega_{1}\left(x_{2 n+1}, x_{2 n+2}\right),\right. \\
\left.\quad \frac{\omega_{2}\left(x_{2 n}, x_{2 n+2}\right)}{2}\right\} \\
\leq \max \left\{\omega_{1}\left(x_{2 n}, x_{2 n+1}\right), \omega_{1}\left(x_{2 n+1}, x_{2 n+2}\right),\right. \\
\left.\quad \frac{\omega_{1}\left(x_{2 n}, x_{2 n+1}\right)+\omega_{1}\left(x_{2 n+1}, x_{2 n+2}\right)}{2}\right\} \\
=\max \left\{\omega_{1}\left(x_{2 n}, x_{2 n+1}\right), \omega_{1}\left(x_{2 n+1}, x_{2 n+2}\right)\right\} .
\end{gathered}
$$

If $M_{T, S}\left(x_{2 n}, x_{2 n+1}\right)=\omega_{1}\left(x_{2 n+1}, x_{2 n+2}\right)$, then we have

$$
\psi\left(\omega_{1}\left(x_{2 n+1}, x_{2 n+2}\right)\right)
$$$$
\leq \gamma\left(\psi\left(M_{T, S}\left(x_{2 n}, x_{2 n+1}\right)\right)\right) \psi\left(M_{T, S}\left(x_{2 n}, x_{2 n+1}\right)\right)
$$$$
\leq \gamma\left(\psi\left(M_{T, S}\left(x_{2 n}, x_{2 n+1}\right)\right)\right) \psi\left(\omega_{1}\left(x_{2 n+1}, x_{2 n+2}\right)\right)^{\varepsilon}
$$$$
<\psi\left(\omega_{1}\left(x_{2 n+1}, x_{2 n+2}\right)\right) \text {. }
$$

Since $\quad \psi$ is strictly increasing, $\omega_{1}\left(x_{2 n+1}, x_{2 n+2}\right)<\omega_{1}\left(x_{2 n+1}, x_{2 n+2}\right)$, which is a contradiction, and this implies that $M_{T, S}\left(x_{2 n}, x_{2 n+1}\right)=\omega_{1}\left(x_{2 n}, x_{2 n+1}\right)$.

Therefore, we get $\omega_{1}\left(x_{n+1}, x_{n+2}\right)<$ $\omega_{1}\left(x_{n}, x_{n+1}\right)$. Further, the sequence $\omega_{1}\left(x_{n}, x_{n+1}\right)$ is positive and nonincreasing. Hence, there exists $r \geq 0$ such that $\lim _{n \rightarrow \infty} \omega_{1}\left(x_{n}, x_{n+1}\right)=r$. Let us show that $r=0$. To the contrary, assume that $r>0$.

Then, we have

$$
\begin{aligned}
& \frac{\psi\left(\omega_{1}\left(x_{n+1}, x_{n+2}\right)\right)}{\psi\left(M_{T, S}\left(x_{n}, x_{n+1}\right)\right)} \\
& \quad \leq \gamma\left(\psi\left(M_{T}\left(x_{n}, x_{n+1}\right)\right)\right. \\
& <1 .
\end{aligned}
$$

On taking the limit in (3.6), we get $\lim _{n \rightarrow \infty} \gamma\left(\psi\left(M_{T}\left(x_{n}, x_{n+1}\right)\right)\right)=1$. Since $\gamma \in$ $\mathrm{F}$, we get

$$
\lim _{n \rightarrow \infty}\left(\psi\left(M_{T}\left(x_{n}, x_{n+1}\right)\right)=0,\right.
$$

which implies that

$$
r=\lim _{n \rightarrow \infty} \omega_{1}\left(x_{n}, x_{n+1}\right)=0 .
$$

This is a contradiction. Next, we shall show that $\left\{x_{n}\right\}$ is a Cauchy sequence. Assume that, $\left\{x_{n}\right\}$ is not a Cauchy sequence. Then there exists $\varepsilon>0$ such that, for all $k \geq 1$, there exists $\quad m(k)>n(k)>k \quad$ with $\omega_{2}\left(x_{n(k)}, x_{m(k)}\right) \geq \varepsilon$. Since $\omega_{1}\left(x_{n(k)}, x_{m(k)}\right) \geq \omega_{2}\left(x_{n(k)}, x_{m(k)}\right)$, then we have $\omega_{1}\left(x_{n(k)}, x_{m(k)}\right) \geq \varepsilon$. Let $m(k)$ be the smallest number satisfying the conditions above. Hence, we have $\omega_{1}\left(x_{n(k)}, x_{m(k)-1}\right)<$ $\varepsilon$. Using the property (3) of modular metric, we have

$$
\begin{aligned}
& \varepsilon \leq \omega_{2}\left(x_{n(k)}, x_{m(k)}\right) \\
& \leq \omega_{1}\left(x_{n(k)}, x_{m(k)-1}\right)+\omega_{1}\left(x_{m(k)-1}, x_{m(k)}\right) \\
& \leq \varepsilon+\omega_{1}\left(x_{m(k)-1}, x_{m(k)}\right) .
\end{aligned}
$$

On taking the limit in (3.8) as $k \rightarrow \infty$, we have

$$
\lim _{k \rightarrow \infty} \omega_{2}\left(x_{n(k)}, x_{m(k)}\right)=\varepsilon
$$

Since

$$
\begin{gathered}
\left|\omega_{1}\left(x_{n(k)}, x_{m(k)-1}\right)-\omega_{2}\left(x_{n(k)}, x_{m(k)}\right)\right| \\
\leq \omega_{1}\left(x_{m(k)}, x_{m(k)-1}\right)
\end{gathered}
$$


we have

$$
\lim _{k \rightarrow \infty} \gamma\left(\psi\left(M_{T, S}\left(x_{n(k)}, x_{m(k)+1}\right)\right)=1,\right.
$$

$$
\lim _{k \rightarrow \infty} \omega_{1}\left(x_{n(k)}, x_{m(k)-1}\right)=\varepsilon .(3.10)
$$

which implies that

Similarly, we obtain

$$
\begin{aligned}
\lim _{k \rightarrow \infty} \omega_{1}\left(x_{m(k)},\right. & \left.x_{n(k)-1}\right) \\
& =\lim _{k \rightarrow \infty} \omega_{1}\left(x_{n(k)-1}, x_{m(k)-1}\right) \\
& =\varepsilon .
\end{aligned}
$$

From Lemma 3.4, we obtain $\psi\left(\omega_{1}\left(x_{n(k)+1}, x_{m(k)+2}\right)\right)=$ $\psi\left(\omega_{1}\left(T x_{n(k)}, S x_{m(k)+1}\right)\right)$

$$
\begin{gathered}
\leq \alpha\left(x_{n(k)}, x_{m(k)+1}\right) \beta\left(x_{n(k)}, x_{m(k)+1}\right) \\
\psi\left(\omega_{1}\left(T x_{n(k)}, S x_{m(k)+1}\right)\right) \\
\leq \gamma\left(\psi\left(M_{T, S}\left(x_{n(k)}, x_{m(k)+1}\right)\right)\right. \\
\psi\left(M_{T, S}\left(x_{n(k)}, x_{m(k)+1}\right)\right),
\end{gathered}
$$

$\lim _{k \rightarrow \infty} M_{T, S}\left(x_{n(k)}, x_{m(k)+1}\right)=0$.

From (3.12) and (3.15), we have $\varepsilon=0$. This is a contradiction. Thus, we obtain that $\left\{x_{n}\right\}$ is a Cauchy sequence. In a similar way, obviously for other cases $\left\{x_{n}\right\}$ is a Cauchy sequence. Since $X_{\omega}$ is a complete modular metric space, it follows that there exists $x_{\iota} \in$ $X_{\omega}$ such that $\lim _{n \rightarrow \infty} \omega_{1}\left(x_{n}, x_{\iota}\right)=0$. Finally, we shall show that $x_{\iota}$ is a common fixed point of $T$ and $S$. Since $\lim _{n \rightarrow \infty} \omega_{1}\left(x_{n}, x_{\imath}\right)=$ 0 , then we have $\lim _{n \rightarrow \infty} \omega_{1}\left(x_{2 n}, x_{l}\right)=$ $\lim _{n \rightarrow \infty} \omega_{1}\left(x_{2 n+1}, x_{l}\right)=0$. By the where

$$
\begin{aligned}
M_{T, S}\left(x_{n(k)}, x_{m(k)+1}\right) & =\max \left\{\omega_{1}\left(x_{n(k)}, x_{m(k)+1}\right), \omega_{1}\left(x_{n(k)}, T x_{n(k)}\right),\right. \\
& \omega_{1}\left(x_{m(k)+1}, S x_{m(k)+1}\right), \\
& \left.\frac{\omega_{2}\left(x_{n(k)}, S x_{m(k)+1}\right)+\omega_{2}\left(x_{m(k)+1}, T x_{n(k)}\right)}{2}\right\} \\
=\max \{ & \omega_{1}\left(x_{n(k)}, x_{m(k)+1}\right), \omega_{1}\left(x_{n(k)}, x_{n(k)+1}\right), \\
& \omega_{1}\left(x_{m(k)+1}, x_{m(k)+2}\right), \\
& \left.\frac{\omega_{2}\left(x_{n(k)}, x_{m(k)+2}\right)+\omega_{2}\left(x_{m(k)+1}, x_{n(k)+1}\right)}{2}\right\} .
\end{aligned}
$$

continuity of $T$ and $S$, we get $\lim _{n \rightarrow \infty} \omega_{1}\left(x_{2 n+1}, T x_{\iota}\right)=\lim _{n \rightarrow \infty} \omega_{1}\left(T x_{2 n}, T x_{\iota}\right)$

$$
=0
$$

and

$$
\begin{gathered}
\lim _{n \rightarrow \infty} \omega_{1}\left(x_{2 n+2}, S x_{\iota}\right)=\lim _{n \rightarrow \infty} \omega_{1}\left(S x_{2 n+1}, S x_{\iota}\right) \\
=0
\end{gathered}
$$

Hence, $x_{\iota}=T x_{\iota}=S x_{\iota}$, it follows that $(T, S)$ has common fixed point.

Theorem 3.7 Let $X_{w}$ be a complete modular metric space, $\alpha, \beta: X_{w} \times X_{w} \rightarrow \mathbb{R}^{+}$be two From (3.9), (3.10) and (3.11), we make an inference that functions, and let $T, S$ be self-mappings on $X_{w}$ satisfying the following conditions:

$$
\lim _{k \rightarrow \infty} M_{T}\left(x_{n(k)-1}, x_{m(k)-1}\right)=\varepsilon .
$$

Hence, we have

1. $(T, S)$ is a pair of generalized $(\alpha, \beta)$-Geraghty contraction type mappings,

$$
\begin{aligned}
& \left.\left.\frac{\psi\left(\omega_{1}\left(x_{n(k)+1}, x_{m(k)+2}\right)\right)}{\psi\left(M _ { T , S } \left(x_{n(k)},\right.\right.} x_{m(k)+1}\right)\right) \\
& \quad \leq \gamma\left(\psi\left(M_{T, S}\left(x_{n(k)}, x_{m(k)+1}\right)\right)\right. \\
& <1 .
\end{aligned}
$$

On taking the limit in (3.13) as $k \rightarrow \infty$, we have

2. $(T, S)$ is triangular $(\alpha, \beta)$-admissible pair,

3. There exists $x_{0} \in X_{w}$ such that $\alpha\left(x_{0}, T x_{0}\right) \geq 1$ and $\beta\left(x_{0}, T x_{0}\right) \geq 1$,

4. If $\left\{x_{n}\right\}$ is a sequence in $X_{w}$ such that $\alpha\left(x_{n}, x_{n+1}\right) \geq 1$ and $\beta\left(x_{n}, x_{n+1}\right) \geq 1$ for all $n$ and $x_{n} \rightarrow x_{\iota} \in X_{w}$ as $n \rightarrow \infty$, then there 
exists a subsequence $\left\{x_{n_{k}}\right\}$ of $\left\{x_{n}\right\}$ such that $\alpha\left(x_{n_{k}}, x_{\iota}\right) \geq 1$ and $\beta\left(x_{n_{k}}, x_{\iota}\right) \geq 1$ for all $k$.

Then $(T, S)$ have a common fixed point.

Proof Similar to the proof of Theorem 3.6, we define a sequence $x_{2 n+2}=S x_{2 n+1}$ and $x_{2 n+1}=T x_{2 n}$ for all $n \geq 0$. This sequence converges to $x_{\iota} \in X_{w}$. By the hypothesis (4) of Theorem 3.7, there exists a subsequence $\left\{x_{n_{k}}\right\}$ of $\left\{x_{n}\right\}$ such that $\alpha\left(x_{n_{k}}, x_{\iota}\right) \geq 1$ and $\beta\left(x_{n_{k}}, x_{l}\right) \geq 1$ for all $k$. From the hypothesis (4) of Theorem 3.7, we have

$$
\begin{aligned}
& \psi\left(\omega_{1}\left(x_{2 n_{k}+1}, T x_{\iota}\right)\right)=\psi\left(\omega_{1}\left(S x_{2 n_{k}}, T x_{\iota}\right)\right) \\
& \leq \alpha\left(x_{2 n_{k}}, x_{\iota}\right) \beta\left(x_{2 n_{k}}, x_{\iota}\right) \psi\left(\omega_{1}\left(S x_{2 n_{k}}, T x_{\iota}\right)\right) \\
& \leq \gamma\left(\psi\left(M_{T, S}\left(x_{2 n_{k}}, x_{\iota}\right)\right) \psi\left(M_{T, S}\left(x_{2 n_{k}}, x_{\iota}\right)\right),\right.
\end{aligned}
$$

where

$$
\begin{aligned}
M_{T, S}\left(x_{2 n_{k}}, x_{\iota}\right)= & \max \left\{\omega_{1}\left(x_{2 n_{k}}, x_{\iota}\right),\right. \\
& \omega_{1}\left(x_{2 n_{k}}, T x_{2 n_{k}}\right), \omega_{1}\left(x_{\iota}, S x_{\iota}\right), \\
& \left.\frac{\omega_{2}\left(x_{2 n_{k}}, S x_{\iota}\right)+\omega_{2}\left(x_{\iota}, T x_{2 n_{k}}\right)}{2}\right\} .
\end{aligned}
$$

Taking the limit in (3.16) as $k \rightarrow \infty$, we get

$$
M_{T, S}\left(x_{2 n_{k}}, x_{\iota}\right)=\omega_{1}\left(x_{\iota}, S x_{\iota}\right)
$$

Since $\omega_{1}\left(x_{l}, S x_{l}\right)>0$ for enough large $k$, we have

$$
M_{T, S}\left(x_{2 n_{k}}, x_{\iota}\right)>0
$$

Since $\gamma \in(0,1)$, we get

$$
\gamma\left(\psi\left(M_{T, S}\left(x_{2 n_{k}}, x_{\iota}\right)\right)\right)<\psi\left(M_{T, S}\left(x_{2 n_{k}}, x_{\iota}\right)\right) .
$$

So we get

$$
\omega_{1}\left(x_{2 n_{k}}, S x_{\iota}\right)<M_{T, S}\left(x_{2 n_{k}}, x_{\iota}\right) .
$$

Letting $k \rightarrow \infty$ in (3.17), we obtain

$$
\omega_{1}\left(x_{l}, S x_{l}\right)<\omega_{1}\left(x_{l}, S x_{l}\right),
$$

which is a contradiction. Thus we obtain that $\omega_{1}\left(x_{l}, S x_{l}\right)=0$. Similarly, we have $\omega_{1}\left(x_{\iota}, T x_{\iota}\right)=0$. Thus, $x_{\iota}=S x_{\iota}=T x_{\iota}$. That is, $(T, S)$ have common fixed point. Finally, we shall show that, $(T, S)$ have a unique common fixed point. To the contrary, assume that $x_{\iota}$ and $y_{\iota}$ are two common fixed point of $(T, S)$ and $x_{\iota} \neq y_{\iota}$. Using the similar process of (3.4) and (3.5), we get

$$
\begin{aligned}
& \psi\left(\omega_{1}\left(x_{\iota}, y_{\iota}\right)\right) \\
& \leq \gamma\left(\psi\left(M_{T, S}\left(x_{\iota}, y_{\iota}\right)\right) \psi\left(M_{T, S}\left(x_{\iota}, y_{\iota}\right)\right),\right.
\end{aligned}
$$

where

$$
\begin{aligned}
& M_{T, S}\left(x_{\iota}, y_{l}\right) \\
& =\max \left\{\omega_{1}\left(x_{\iota}, y_{l}\right), \omega_{1}\left(x_{\iota}, T x_{\iota}\right), \omega_{1}\left(y_{l}, S y_{\iota}\right),\right. \\
& \left.\frac{\omega_{2}\left(x_{\iota}, S y_{l}\right)+\omega_{2}\left(y_{\iota}, T x_{l}\right)}{2}\right\} .
\end{aligned}
$$

Thus,

$\omega_{1}\left(x_{l}, y_{l}\right)=0$ if not, this is a contradiction. Therefore $(T, S)$ have a unique common fixed point.

If $S=T$ in Theorem 3.6, then we have

$$
\begin{aligned}
M_{T}(x, y)=\max \left\{\omega_{1}(x, y), \omega_{1}(x, T x),\right. \\
\left.\omega_{1}(y, T y), \frac{\omega_{2}(x, T y)+\omega_{2}(y, T x)}{2}\right\} .
\end{aligned}
$$

We have the following corollary.

Corollary 3.8 Let $X_{w}$ be a complete modular metric space, $\alpha, \beta: X_{w} \times X_{w} \rightarrow \mathbb{R}^{+}$be functions, and let $T$ be a self-mapping on $X_{w}$ satisfying the following conditions:

1. $T$ is a generalized $(\alpha, \beta)-$ Geraghty contraction type mapping,

2. $T$ is triangular $(\alpha, \beta)$-admissible mapping, 
3. There exists $x_{0} \in X_{w}$ such that If $S=T, M(x, y)=$ $\alpha\left(x_{0}, T x_{0}\right) \geq 1$ and $\beta\left(x_{0}, T x_{0}\right) \geq 1$,

$\max \left\{\omega_{1}(x, y), \omega_{1}(x, T x), \omega_{1}(y, T y)\right\}$

4. If $\left\{x_{n}\right\}$ is a sequence in $X_{w}$ such that $\alpha\left(x_{n}, x_{n+1}\right) \geq 1$ and $\beta\left(x_{n}, x_{n+1}\right) \geq 1$ for all $n$ and $x_{n} \rightarrow x_{\iota} \in X_{w}$ as $n \rightarrow \infty$, then there exists a subsequence $\left\{x_{n_{k}}\right\}$ of $\left\{x_{n}\right\}$ such that $\alpha\left(x_{n_{k}}, x_{\iota}\right) \geq 1$ and $\beta\left(x_{n_{k}}, x_{\iota}\right) \geq 1$ for all $k$.

Then $T$ has a fixed point $x_{\iota} \in X_{w}$ and $\left\{T^{n} x_{0}\right\}$ converges to $x_{\iota}$.

Corollary 3.8 generalize results of [12] and [2]. $T$ is continuous instead of the hypothesis (4) of Corollary 3.8, then, $T$ has a fixed point.

If $T=S$ and

$\left.\alpha(x, y) \omega_{1}(T x, T y) \leq \gamma\left(M_{T}(x, y)\right)\right) M_{T}(x, y)$,

where

$$
\begin{array}{r}
M_{T}(x, y)=\max \left\{\omega_{1}(x, y), \omega_{1}(x, T x),\right. \\
\left.\omega_{1}(y, T y), \frac{\omega_{2}(x, T y)+\omega_{2}(y, T x)}{2}\right\},
\end{array}
$$

Then we get the following corollary.

Corollary 3.9 Let $X_{w}$ be a complete modular metric space, $\alpha: X_{w} \times X_{w} \rightarrow \mathbb{R}^{+}$be a function, and $T$ be a self-mapping on $X_{w}$ satisfying the following conditions:

1. $T$ is a generalized $\alpha$-Geraghty contraction type mapping,

2. $T$ is a triangular $\alpha-$ admissible mapping,

3. there exists $x_{0} \in X_{w}$ such that $\alpha\left(x_{0}, T x_{0}\right) \geq 1$,

4. if $\left\{x_{n}\right\}$ is a sequence in $X_{w}$ such that $\alpha\left(x_{n}, x_{n+1}\right) \geq 1$ for all $n$ and $x_{n} \rightarrow x_{\iota} \in X_{w}$ as $n \rightarrow \infty$, then there exists a subsequence $\left\{x_{n_{k}}\right\}$ of $\left\{x_{n}\right\}$ such that $\alpha\left(x_{n_{k}}, x_{\iota}\right) \geq 1$ for all $k$. Then $T$ has a fixed point $x_{\iota} \in X_{w}$ and $\left\{T^{n} x_{0}\right\}$ converges to $x_{\iota}$

and $\beta(x, y)=1$ for all $x, y \in X_{w}$ in Theorem 3.6 , then we get the following corollary.

Corollary 3.10 Let $X_{w}$ be a complete modular metric space, $\alpha: X_{w} \times X_{w} \rightarrow \mathbb{R}^{+}$be a function, and $T$ be a self-mapping on $X_{w}$ satisfying the following conditions:

1. $T$ is a $\alpha$-Geraghty contraction type mapping,

2. $T$ is a triangular $\alpha$-admissible mapping,

3. There exists $x_{0} \in X_{w}$ such that $\alpha\left(x_{0}, T x_{0}\right) \geq 1$,

4. If $\left\{x_{n}\right\}$ is a sequence in $X_{w}$ such that $\alpha\left(x_{n}, x_{n+1}\right) \geq 1$ for all $n$ and $x_{n} \rightarrow x_{\iota} \in X_{w}$ as $n \rightarrow \infty$, then there exists a subsequence $\left\{x_{n_{k}}\right\}$ of $\left\{x_{n}\right\}$ such that $\alpha\left(x_{n_{k}}, x_{l}\right) \geq 1$ for all $k$.

Then $T$ has a fixed point $x_{\iota} \in X_{w}$ and $\left\{T^{n} x_{0}\right\}$ converges to $x_{\iota}$.

The corollary is similar when $T$ is assumed to be continuous in Corollary 3.9 and Corollary 3.10, and so $T$ has a fixed point.

Example 3.11 Let $X_{\omega}=[0, \infty), \omega_{1}(x, y)=$ $|x-y|, \quad \omega_{\lambda}(x, y)=\frac{1}{\lambda}|x-y|$. Define the mappings $\alpha, \beta: X_{w} \times X_{w} \rightarrow \mathbb{R}^{+}$, and consider the mappings $T, S: X_{\omega} \rightarrow X_{\omega}, \gamma \in \mathrm{F}$, such that $\gamma(0)=0, \gamma(t)=\frac{7}{8}$ for all $t \geq 0$ and let $\psi(t)=\frac{t}{2}$. For all $x, y \in X_{\omega}$,

$$
\begin{gathered}
T x= \begin{cases}\frac{x}{5}, & x \in[0,1], \\
0, & \text { otherwise }\end{cases} \\
S x= \begin{cases}\frac{x}{2}, & x \in[0,1] \\
2 x-1, & \text { otherwise }\end{cases}
\end{gathered}
$$


and

$$
\alpha(x, y)=\beta(x, y)= \begin{cases}1, & (x, y) \in[0,1] \\ 0, & \text { otherwise }\end{cases}
$$

Now, we show that $(T, S)$ is an $(\alpha, \beta)$-admissible mapping. $X_{\omega}=[0,1]$ is a complete modular metric space. Let $x, y \in$ $X_{\omega}, \quad \alpha(x, y) \geq 1$ and $\beta(x, y) \geq 1, \quad x, y \in$ $0,1]$. For all $x \in 0,1]$, we have $T x \leq 1$ and $S x \leq 1$. Then $\alpha(T x, S y) \geq 1, \alpha(S x, T y) \geq 1$ and $\beta(T x, S y) \geq 1, \beta(S x, T y) \geq 1$. For $x_{0}=$ 0 , we have $\alpha\left(x_{0}, T x_{0}\right) \geq 1$ and $\beta\left(x_{0}, T x_{0}\right) \geq$ 1. Therefore, the assertions hold. $T$ and $S$ are not continuous mappings. Let $\left\{x_{n}\right\}$ is a sequence in $X_{w}$ such that $\alpha\left(x_{n}, x_{n+1}\right) \geq 1$ and $\beta\left(x_{n}, x_{n+1}\right) \geq 1$ for all $n$ and $x_{n} \rightarrow x_{\iota} \in$ $X_{w}$ as $n \rightarrow \infty$, then there exists a subsequence $\left\{x_{n_{k}}\right\}$ of $\left\{x_{n}\right\}$ such that $\alpha\left(x_{n_{k}}, x_{\iota}\right) \geq 1$ and $\beta\left(x_{n_{k}}, x_{\iota}\right) \geq 1$ for all $k$. Later, we show that $(T, S)$ is a pair of generalized $(\alpha, \beta)$-Geraghty contraction type mapping. For all $x, y \in 0,1]$,

$$
\begin{aligned}
M_{T, S}(x, y)= & \max \left\{\omega_{1}(x, y), \omega_{1}(x, T x),\right. \\
& \left.\omega_{1}(y, S y), \frac{\omega_{2}(x, S y)+\omega_{2}(y, T x)}{2}\right\} \\
& = \begin{cases}|x-y|, & 0 \leq y \leq \frac{x}{5} \\
\frac{4 x}{5}, & \frac{x}{5}<y \leq 1\end{cases}
\end{aligned}
$$

and

$$
\begin{aligned}
\alpha(x, y) \beta(x, y) & \psi\left(\omega_{1}(T x, S y)\right) \\
& =\psi\left(\left|\frac{x}{5}-\frac{y}{2}\right|\right)=\frac{1}{2}\left|\frac{x}{5}-\frac{y}{2}\right|
\end{aligned}
$$

Therefore, $(T, S)$ holds $(3.1)$, and so, $(T, S)$ is a pair of generalized $(\alpha, \beta)$-Geraghty contraction type mapping. Obviously, a common fixed point of $(T, S)$ is $x_{\iota}=0$.

\section{Periodic Point Results}

In this section we prove some periodic point results for self-mappings on a complete modular metric space. It is an obvious fact that, if $x$ is a fixed point of $T$ (i.e. $\operatorname{Fix}(T):=$ $\{x \in X: T x=x\}$ ), then $x$ is also a fixed point of $T^{n}$ for every $n \in N$. Now, we give the following definition.

Definition 4.1 (Jeong and Rhoades, 2005) $A$ mapping $T: X \rightarrow X$ is said to have property $(P)$ if $F i x\left(T^{n}\right)=F i x(T)$ for every $n \in \mathbb{N}$.

For further details on these property, we refer to (Jeong and Rhoades, 2005). Now, we use the property $(P)$ in modular metric spaces.

Theorem 4.2 Let $X_{w}$ be a complete modular metric space, and $T$ be self-mappings on $X_{w}$ satisfying the following conditions:

1. there exists $\tau>0$ and a function $\psi \in \mathrm{F}$ and $\alpha, \beta: X_{w} \times X_{w} \rightarrow \mathbb{R}^{+}$be two functions such that

$\alpha(x, T x) \beta(x, T x) \psi\left(\omega_{1}\left(T x, T^{2} x\right)\right)$

$\leq \gamma\left(\psi\left(M_{T}(x, T x)\right)\right) \psi\left(M_{T}(x, T x)\right)$,

where

$M_{T}(x, T x)=\max \left\{\omega_{1}(x, T x), \omega_{1}(x, T x)\right.$,

$$
\left.\omega_{1}\left(T x, T^{2} x\right), \frac{\omega_{2}\left(x, T^{2} x\right)+\omega_{2}(T x, T x)}{2}\right\},
$$

holds for all $x \in X_{\omega}$ with, $\omega_{1}\left(T x, T^{2} x\right)>0$,

2. There exists $x_{0} \in X_{w}$ such that $\alpha\left(x_{0}, T x_{0}\right) \geq 1$,

3. $T$ is a triangular $\alpha$-admissible mapping,

4. If $\left\{x_{n}\right\}$ is a sequence in $X_{w}$ such that $\alpha\left(x_{n}, x_{n+1}\right) \geq 1$ for all $n \in \mathbb{N}$ and $\omega_{1}\left(x_{n}, x\right) \rightarrow 0, \quad$ as $\quad n \rightarrow \infty$, then $\omega_{1}\left(T x_{n}, T x\right) \rightarrow 0$ as $n \rightarrow \infty$.

5. If $t \in F i x\left(T^{n}\right)$ and $t \notin F i x(T)$, then $\alpha\left(T^{n-1} t, T^{n} t\right) \geq 1$.

Then T has property $(P)$. 
Proof Let $x_{0} \in X_{w}$ such that $\alpha\left(x_{0}, T x_{0}\right) \geq$ 1. Define a sequence $\left\{x_{n}\right\}$ by $x_{n}=T^{n} x_{n}=$ $T x_{n-1}$. By the hypothesis (2) of the Theorem 4.2 and using (3.2), we obtain

$$
\alpha\left(x_{n}, x_{n+1}\right) \geq 1
$$

for all $n \in \mathbb{N}$. If there exists $n_{0} \in \mathbb{N}$ such that $x_{n_{0}}=x_{n_{0}+1}=T x_{n_{0}}$, then $x_{n_{0}}$ is a fixed point of $T$ and the proof is finished. Therefore, we suppose $x_{n} \neq x_{n+1}$ or $\omega_{1}\left(T x_{n-1}, T^{2} x_{n-1}\right)>0$ for all $n \in \mathbb{N}$. In view of (3.2) and (3.3), we have

$\psi\left(\omega_{1}\left(x_{n}, x_{n+1}\right)\right) \leq$ $\gamma\left(\psi\left(M_{T}\left(x_{n-1}, T x_{n-1}\right)\right)\right) \psi\left(M_{T}\left(x_{n-1}, T x_{n-1}\right)\right)$

By using a similar reasoning as in the proof of Theorem 3.6, we get that the sequence $\left\{x_{n}\right\}$ is a $\omega$-Cauchy sequence. Hence, the $\omega$-completeness of $X_{w}$ ensures that there exists $x_{\iota} \in X_{\omega}$ such that $x_{n} \rightarrow x_{\iota}$ as $n \rightarrow \infty$. The hypothesis (4) of Theorem 4.2, we get $\omega_{1}\left(x_{n+1}, T x_{l}\right)=\omega_{1}\left(T x_{n}, T x_{l}\right) \rightarrow 0$ as $n \rightarrow$ $\infty$, that is $x_{\iota}=T x_{\iota}$. Hence, $T$ has a fixed point and $\operatorname{Fix}\left(T^{n}\right)=\operatorname{Fix}(T)$ is true for $n=$ 1. Let $n>1$ and assume that $t \in \operatorname{Fix}\left(T^{n}\right)$ and $t \notin \operatorname{Fix}(T)$ such that $w_{1}(t, T t)>0$. From the hypothesis (1) of Theorem 4.2, we get

$$
\begin{aligned}
& \psi\left(\omega_{1}(t, T t)\right) \\
= & \psi\left(\omega_{1}\left(T\left(T^{n-1} t\right), T^{2}\left(T^{n-1} t\right)\right)\right. \\
\leq & \alpha\left(T^{n-1} t, T\left(T^{n-1} t\right)\right) \beta\left(T^{n-1} t, T\left(T^{n-1} t\right)\right) \\
& \psi\left(\omega_{1}\left(T\left(T^{n-1} t\right), T^{2}\left(T^{n-1} t\right)\right)\right) \\
\leq & \gamma\left(\psi\left(M_{T}\left(T^{n-1} t, T\left(T^{n-1} t\right)\right)\right)\right) \\
& \psi\left(M_{T}\left(T^{n-1} t, T\left(T^{n-1} t\right)\right)\right),
\end{aligned}
$$

where

$$
\begin{gathered}
M_{T}\left(T^{n-1} t, T\left(T^{n-1} t\right)\right) \\
=\max \left\{\omega_{1}\left(T^{n-1} t, T\left(T^{n-1} t\right)\right),\right. \\
\omega_{1}\left(T^{n-1} t, T\left(T^{n-1} t\right)\right),
\end{gathered}
$$

$$
\begin{array}{r}
\omega_{1}\left(T\left(T^{n-1} t\right), T^{2}\left(T^{n-1} t\right)\right), \\
\left.\frac{\omega_{2}\left(T^{n-1} t, T^{2}\left(T^{n-1} t\right)\right)+\omega_{2}\left(T\left(T^{n-1} t\right), T\left(T^{n-1} t\right)\right)}{2}\right\} . \\
=\max \left\{\omega_{1}\left(T^{n-1} t, T\left(T^{n-1} t\right)\right)\right. \\
\omega_{1}\left(\left(T\left(T^{n-1} t\right), T^{2}\left(T^{n-1} t\right)\right)\right\} .
\end{array}
$$

For $\gamma \in \mathrm{F}$, and if

$$
\begin{aligned}
& \max \left\{\omega_{1}\left(T^{n-1} t, T\left(T^{n-1} t\right)\right),\right. \\
& \left.\omega_{1}\left(T\left(T^{n-1} t\right), T^{2}\left(T^{n-1} t\right)\right)\right\}=\omega_{1}(t, T t),
\end{aligned}
$$

then, we obtain

$$
\begin{aligned}
& \psi\left(\omega_{1}(t, T t)\right) \\
& \leq \gamma\left(\psi\left(M_{T}\left(T^{n-1} t, T\left(T^{n-1} t\right)\right)\right)\right) \psi\left(\omega_{1}(t, T t)\right),
\end{aligned}
$$

which is a contradiction. Thus, we deduce that $\omega_{1}(t, T t)=0$. If

$$
\begin{aligned}
& \max \left\{\omega_{1}\left(T^{n-1} t, T\left(T^{n-1} t\right)\right)\right. \\
& \left.\omega_{1}\left(T\left(T^{n-1} t\right), T^{2}\left(T^{n-1} t\right)\right)\right\} \\
& =\omega_{1}\left(T^{n-1} t, T\left(T^{n-1} t\right)\right)
\end{aligned}
$$

then, we write

$$
\begin{aligned}
& \psi\left(\omega_{1}(t, T t)\right) \\
\leq & \gamma\left(\psi\left(M_{T}\left(T^{n-1} t, T\left(T^{n-1} t\right)\right)\right)\right) \\
& \psi\left(\omega_{1}\left(T^{n-1} t, T\left(T^{n-1} t\right)\right)\right) \\
\leq & \psi\left(\omega_{1}\left(T^{n-1} t, T\left(T^{n-1} t\right)\right)\right) .
\end{aligned}
$$

Since $\psi$ is strictly increasing, we have $\omega_{1}\left(T\left(T^{n-1} t\right), T^{2}\left(T^{n-1} t\right)\right)$

$$
\leq \omega_{1}\left(T^{n-1} t, T\left(T^{n-1} t\right)\right) .
$$

Thus, $\omega_{1}\left(T\left(T^{n-1} t\right), T^{2}\left(T^{n-1} t\right)\right)$ is positive and nonincreasing. So, there exists $r \geq$ 0 such that $\lim _{n \rightarrow \infty} \omega_{1}\left(T^{n-1} t, T\left(T^{n-1} t\right)\right)=$ $r$. Let us show that $r=0$. To the contrary, assume that $r>0$. Using the similar process of (3.6) and (3.7), we have that $\lim _{n \rightarrow \infty} \gamma\left(\psi\left(M_{T}\left(T^{n-1} t, T\left(T^{n-1} t\right)\right)\right)\right)=1$.

Since $\gamma \in$ F, we obtain

$$
\lim _{n \rightarrow \infty} \psi\left(M_{T}\left(T^{n-1} t, T\left(T^{n-1} t\right)\right)\right)=0 .
$$


In the sequel, we obtain $r=$ differential equation", Adv. Differ. Equ., $\lim _{n \rightarrow \infty} \omega_{1}\left(T^{n-1} t, T\left(T^{n-1} t\right)\right)=0$, and so,

$$
\lim _{n \rightarrow \infty} \omega_{1}\left(T\left(T^{n-1} t\right), T^{2}\left(T^{n-1} t\right)\right)=0,
$$

which is a contradiction. Thus, we make an inference that $\omega_{1}(t, T t)=0$. Therefore,

$F i x\left(T^{n}\right)=F i x(T)$ for all $n \in \mathbb{N}$ and $T$ has property $(P)$.

Acknowledgement: The authors is thankful to the learned referees and editor also Tübitak.

\section{References}

Amini-Harandi, A. and Emani, H. 2010. "A fixed point theorem for contraction type maps in partially ordered metric spaces and application to ordinary differential equations", Nonlinear Anal., 72, 2238-2242. doi:10.1016/j.na. 2009.10.023.

Arshad, M., Hussain, A. and Azam, A. 2016. "Fixed point of $\alpha$-Geraghty contraction with applications", U.P.B. Sci. Bull., Series A, 78-2.

Aydi, H. 2015. " $\alpha$-implicit contractive pair of mappings on quasi b-metric spaces and application to integral equations", Accepted in J. Nonlinear Convex Anal.

Azadifar, B., Maramaei, M. and Sadeghi, G. 2013. "On the modular G-metric spaces and fixed point theorems", J. Nonlinear Sci. Appl., 6(4), 293-304.

Banach, S. 1922. "Sur les opérationes dans les ensembles abstraits et leur application aux équation intégrales", Fundam. Math., 3, 133181.

Caballero, J., Harjani, J. and Sadarangani, K. 2012. "A best proximity point theorem for Geraghty-contractions", Fixed Point Theory Appl., Article ID 231.

Chaipunya, P., Cho, YE. and Kumam, P. 2012. "Geraghty-type theorems in modular metric spaces with an application to partial Article ID 83.

Chaipunya, P., Mongkolkeha, C., Sintunavarat, W. and Kumam, P. 2012. "Fixed-point theorems for multivalued mappings in modular metric spaces", Abstr Appl Anal., 2012, 14. Article ID 503504.

Chandok, S. 2015. "Some fixed point theorems for $(\alpha, \beta)$-admissible Geraghty type contractive mappings and related results", Math. Sci., 9, 127-13, doi: 10.1007/s40096-015-0159-4.S.

Chistyakov, VV. 2010. "Modular metric spaces, I: basic concepts", Nonlinear Anal., 72, 1-14, doi:10.1016/j.na.2009.04.057.

Chistyakov, VV. 2011. "A fixed point theorem for contractions in modular metric spaces", Perprint submited to arxiv.

Cho, SH., Bae, JS. and Karapınar, E. 2013. "Fixed point theorems for $\alpha$-Geraghty contraction type maps in metric spaces", Fixed Point Theory Appl., Article 1, 329.

Geraghty, M. 1973. "On contractive mappings", Proc Am Math Soc., 40, 604608.

Eshaghi Gordji, M., Ramezani, M., Cho, YJ. and Pirbavafa, S. 2012. "A generalization of Geraghty's theorem in partially ordered metric spaces and application to ordinary differential equations", Fixed Point Theory Appl., 74.

Hussain, N., Latif, A. and Iqbal, I. 2015. "Fixed point results for generalized $F$-contractions in modular metric and fuzzy metric spaces", Fixed Point Theory Appl., 158.

Jeong, G S. and Rhoades B E. 2005. "Maps for which $F(T)=F\left(T^{n}\right)$ ", Fixed Point Theory Appl., 6, 87-131.

Karapınar, E. and Samet, B. 2014. "Note on ' $\psi$-Geraghty type contractions"', Fixed Point Theory Appl., Article ID 26.

Kuaket, K. and Kumam, P. 2011. "Fixed point for asymptotic pointwise contractions 
in modular space", Appl. Math. Lett., 24, 1795-1798.

Kumam, P. 2004. "Some geometric properties and fixed point theorem in modular spaces", In: Garcia Falset J, Fuster L, Sims B (eds.) Fixed Point Theorem and its Applications, 173-188.

Mongkolkeha, C., Sintunavarat, W. and Kumam, P. 2011. "Fixed point theorems for contraction mappings in modular metric spaces", Fixed Point Theory Appl., 93, doi:10.1186/1687-1812-2011-93165H.

Mongkolkeha, C., Cho, YE. And Kumam, P. 2013. "Best proximity points for Geraghty's proximal contraction mappings", Fixed Point Theory Appl., Article ID 180.

Padcharoen, A., Gopal, D., Chaipunya, P. and Kumam, P. 2016. "Fixed point and periodic point results for $\alpha$-type $F$-contractions in modular metric spaces", Fixed Point Theory and Applications, 39, DOI 10.1186/s13663-016-0525-4R.

Samet, B., Vetro, C. and Vetro, P. 2012. "Fixed point theorems for $\alpha-$ $\psi$-contractive mappings", Nonlinear Anal., 75, 2154-2165. 